ECP-2008-GEO-318007

Plan4all

\title{
Workshops and Conferences
}

\author{
Deliverable number \\ D9.7.1 \\ Dissemination level \\ Public \\ Delivery date \\ $30^{\text {th }}$ November 2009 \\ Status \\ Final \\ Author(s) \\ Tomas Mildorf (UWB) \\ Mauro Salvemini (EUROGI)

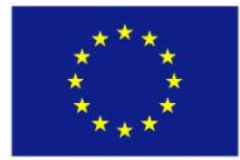 \\ eContentplus
}

This project is funded under the $e$ Contentplus programme ${ }^{1}$, a multiannual Community programme to make digital content in Europe more accessible, usable and exploitable.

1 OJ L 79, 24.3.2005, p. 1. 


\section{Table of Contents}

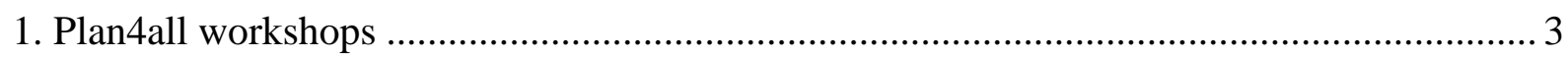

1.1 Workshop during the Joint International Conference in Prague ...................................... 3

1.2 Workshop during the Geomatics in projects conference in Pilsen.................................... 3

1.3 Workshop during the AMFM conference in Rome ………............................................ 3

1.4 Workshop with external experts in Rome ............................................................. 4

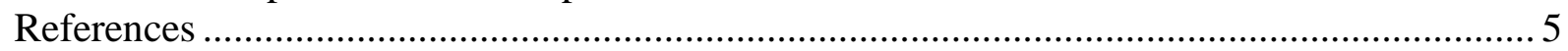




\section{Plan4all workshops}

There were 4 Plan4all workshops held in Month 1, Month 5 and Month 6. Below you can see their description.

\subsection{Workshop during the Joint International Conference in Prague}

Date: $13^{\text {th }}$ May 2009

Venue: Prague, Czech Republic

Notes: Technological solutions and activities of the Plan4all partners were introduced.

\subsection{Workshop during the Geomatics in projects conference in Pilsen}

Date: $16^{\text {th }}$ September 2009

Venue: Castle Kozel, Czech Republic

Notes: The conference was focused on multi-disciplinary introduction of various geo-related projects. There were three sections:

- $\quad$ Geomatics in National Heritage

- Geomatics in Spatial Planning (Plan4all Workshop)

- $\quad$ Geomatics in Health Care

The Plan4all workshop was focused on Czech professionals (e.g. GIS department at regional authority of Pilsen Region). Techniques, best practices and innovations related to spatial planning were discussed.

Eva Pauknerova (former JRC Ispra employee involved in the INSPIRE) made her presentation.

\subsection{Workshop during the AMFM conference in Rome}

Date: $24^{\text {th }}$ September 2009

Venue: Rome, Italy

Notes: AMFM Conference 2009 was focused on the following issues:

- $\quad$ addressing policy and strategic issues related to the growth of digital geographic information in Italy as an opportunity for economic, cultural, social and technological developments;

- national act regarding the fostering of how to use GI for services to the citizens (presented by a Member of Italian Parliament); 
Half day Plan4all workshop was focused on the following issues :

- Italian community (mainly at regional and sub national level) was informed about the project tasks and the way forward how to treat specific WP such as metadata and data model;

- $\quad$ a cooperation between the EURADIN project and Plan4all.

\subsection{Workshop with external experts in Rome}

Date: $5^{\text {th }}-6^{\text {th }}$ October 2009

Venue: Rome, Italy

Notes: 7 external experts were invited to participate in this review of WP2 outcomes:

- Zorica Nedovic-Budic, University College Dublin

- Stan Geertman, Univ. Utrecht, Netherlands

- Michele Campagna, University of Cagliari, Italy

- Paul Janssen, Geonovum, Netherlands

- Pawel Decewicz, CGP, Poland

- Gabor Remetey-Fueloep, HUNAGI, Hungary

- Matti Holopainen, ALFRA, Finland

All of these experts were intensively commenting the content of all outputs from WP2. All the comments were taken into account and incorporated in the final versions of the deliverables. Here are some of the comments:

Zorica Nedovic: I have reviewed the INSPIRE requirement analysis document that you distributed. I found the recommendations at the end most useful and crucial as the project is starting to get into the specifics. The raw data was a bit harder to understand in terms of application to the new data models / application schema, but I can see that the project is on the right track. I expect that the recommendations will translate in the very specific proposals in terms of elements of the feature catalog and data model that has elements of planning terminology and process infused. I suppose you have some feedback mechanism planned for that phase of the project as well. I also found the analyses and reports done for the user requirements analyses of ultimate value (and there has to be an impressive amount of data collection and organisation done for that part - excellent work, indeed).

Michele Campagna: I think in the short time you had for the tasks you have made a great work and the potential for the deliverables in progress is high for supporting further project activities, while some of them may be very interesting also for external audience.

Please note that my comments below refer to the State of development at the time of the workshop, since I have not reviewed further documents afterwards.

D2.1 - I think profiling Member States (MS) planning system frameworks according to a comparative perspective is an essential starting point for further Plan4all development. However, to me some further efforts are needed to depict current developments in SDI in the $M S s$ and the relationships in spatial planning.

D2.2 - The draft already contains a good collection of interesting materials with regards with technology (part 1) and data accuracy issues (part 2). 
To me part 1, which already record a lot of interesting materials of existing technology and their possible application in spatial planning, it still need more work to put all in framework. Some tables or chart may help to synthesise and offer a better critical perspective. Moreover, I think more attention should be paid in the report to Service Oriented Architectures.

D2.4 - The material presented in the report is of great interest. The structure of the report is also very good. I look forward to see the final version of the document.

\section{References}

INSPIRE Directive: http://eur-lex.europa.eu/JOHtml.do?uri=OJ:L:2007:108:SOM:EN:HTML

INSPIRE Website: http://inspire.jrc.ec.europa.eu/

Plan4all Grant Agreement, Annex I - Description of Work 